\title{
Padrões de consumo de energia no sector residencial: estudo de caso no 14o Bairro Nhaconjo, Cidade da Beira, Moçambique
}

\section{Manuel Tomás Manuel $^{1}$ e Alfiado Victorino ${ }^{2}$}

\author{
${ }^{1}$ Universidade Licungo. Faculdade de Ciências e Tecnologia. Curso de Física. \\ Extensão da Beira. Moçambique. E-mail: mtmanuel136@gmail.com. \\ ${ }^{2}$ Universidade Licungo. Faculdade de Ciências e Tecnologia. Extensão da Beira. \\ Moçambique.
}

Resumo. Com a finalidade de compreender as dinâmicas envolvidas no uso de energia nas famílias, este artigo analisa os padrões de consumo doméstico de energia dos agregados familiares residentes no 14을 Bairro Nhaconjo, na Cidade da Beira, no centro de Moçambique. Os dados foram recolhidos usando, primeiramente, um levantamento bibliográfico e documental e depois utilizou-se inquérito por questionário e medições directas como instrumento de colecta de dados. Os resultados mostraram que os padrões de consumo doméstico de energia foram muito diferenciados, e em termos do consumo de energia útil, destacase a electricidade com uma média de $217 \mathrm{MJ} / \mathrm{mês}$ e $444,5 \mathrm{kWh} /$ per capita, o carvão vegetal com $1.199 \mathrm{MJ} / \mathrm{mês}$ e $421,8 \mathrm{~kg} /$ per capita, o GLP com $528 \mathrm{MJ} / \mathrm{mês}$ e $40,9 \mathrm{~kg} /$ per capita, a lenha com $278 \mathrm{MJ} / \mathrm{mês}$ e $34,3 \mathrm{~kg} /$ per capita, a serradura com $109 \mathrm{MJ} / \mathrm{mês}$ e $3,9 \mathrm{~kg} /$ per capita, a querosene com $31 \mathrm{MJ} /$ mês e $0,37 \mathrm{~L} /$ per capita, a vela com $46 \mathrm{MJ} / \mathrm{mês}$ e 4 velas/per capita, e por último a pilha com $4,8 \times 10^{-13} \mathrm{MJ} /$ mês e $4,4 \mathrm{~V} /$ per capita. Os combustíveis mais preferidos pelas famílias em causa é a electricidade e o carvão vegetal.

Palavras-chave: Padrões de consumo de energia; Sector doméstico; 14ํㅡㄹ Bairro Nhaconjo.

\begin{abstract}
Energy consumption standards in the residential sector: Case study in 14th Nhaconjo Neighborhood, Beira City, Mozambique. In order to understand the dynamics involved in household energy use, this paper analyses household energy consumption patterns of households residing in the 14th Nhaconjo Neighborhood in Beira City, central Mozambique. Data were collected using, first, a bibliographic and documentary survey and then a questionnaire survey and direct measurements were used as a data collection instrument. The results showed that domestic energy consumption patterns were very different, and in terms of useful energy consumption, electricity stood out with an average of $217 \mathrm{MJ} /$ month and $444.5 \mathrm{kWh} /$ per capita, charcoal with 1,199 MJ/month and 421,8 kg/per capita, LPG with
\end{abstract}

Recebido

$22 / 03 / 2020$

Aceito

28/07/2020

Disponível on line $30 / 07 / 2020$

Publicado

$31 / 08 / 2020$

Acesso aberto

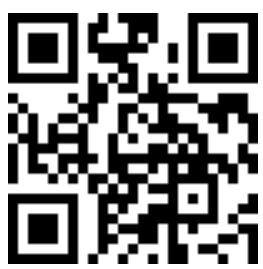

ORCID

() 0000-0001-5101-6326 Manuel Tomás Manuel

(D) 0000-0003-3134-3607 Alfiado Victorino

ISSN 2359-1412/RBGAS-2020-0046/2020/7/16/12/633

Rev. Bras. Gest. Amb. Sustent.

http://revista.ecogestaobrasil.net 
$528 \mathrm{MJ} /$ month and 40,9 $\mathrm{kg} /$ per capita, firewood with $278 \mathrm{MJ} / \mathrm{month}$ and $34,3 \mathrm{~kg} /$ per capita, the sawdust with $109 \mathrm{MJ} /$ month and $3.9 \mathrm{~kg} /$ per capita, the kerosene with $31 \mathrm{MJ} /$ month and $0.37 \mathrm{~L} /$ per capita, the candle with $46 \mathrm{MJ} /$ month and 4 candles/per capita, and lastly the stack with $4.8 \times 10^{-13}$ $\mathrm{MJ} /$ month and $4.4 \mathrm{~V} /$ per capita. The most preferred fuels of the households concerned are electricity and charcoal.

Keywords: Energy consumption patterns; Domestic sector; 14th Nhaconjo Neighborhood.

Resumen. Normas de consumo de energía en el sector residencial: Estudio de caso en el 14o Barrio de Nhaconjo, Ciudad de Beira, Mozambique. Con el fin de comprender la dinámica involucrada en el uso de energía en el hogar, este documento analiza los patrones de consumo de energía de los hogares que residen en el 14to vecindario de Nhaconjo en la ciudad de Beira, en el centro de Mozambique. Los datos se recopilaron utilizando, primero, una encuesta bibliográfica y documental y luego una encuesta de cuestionario y mediciones directas se utilizaron como un instrumento de recopilación de datos. Los resultados mostraron que los patrones de consumo de energía doméstica eran muy diferentes, y en términos de consumo de energía útil, la electricidad se destacó con un promedio de $217 \mathrm{MJ} /$ més y $444.5 \mathrm{kWh} /$ per capita, el carbón con $1.199 \mathrm{MJ} /$ més y 421,8 kg/per capita, GLP con $528 \mathrm{MJ} /$ més y $40,9 \mathrm{~kg} /$ per capita, leña con $278 \mathrm{MJ} /$ més y $34,3 \mathrm{~kg} /$ per capita, el aserrín con $109 \mathrm{MJ} /$ més y $3.9 \mathrm{~kg} /$ per capita, el queroseno con $31 \mathrm{MJ} /$ més y $0.37 \mathrm{~L} /$ per capita, la vela con $46 \mathrm{MJ} / \mathrm{més}$ y 4 velas/per capita, y finalmente la pila con $4.8 \times 10^{-13} \mathrm{MJ} / \mathrm{més}$ y $4.4 \mathrm{~V} /$ per capita. Los combustibles más preferidas de los hogares afectados son la electricidad y el carbón.

Palabras clave: Patrones de consumo de energía; Sector doméstico; XIV Barrio Nhaconjo.

\section{Introdução}

A energia, em suas mais variadas formas foi é e sempre será, um recurso essencial para o funcionamento e manutenção da vida em sociedade (Fournier e Penteado, 2010). 0 desenvolvimento económico e os altos padrões de vida são processos complexos que compartilham um denominador comum, a disponibilidade de suprimentos adequados e confiáveis de energia. Ela se destaca como um dos recursos fundamentais na sociedade contemporânea, tornando-se indispensável para a realização de diversas actividades diárias. A vida nas pequenas e grandes cidades depende significativamente do uso de várias formas de energia para realização de diversas actividades como alimentação, conservação de alimentos, comunicação, lazer, trabalho, estudo, entre outras (Hinrichs et al., 2013).

Estudos feitos por Arthur et al. (2011), Burgsdorff (2017), Mahumane e Mulder (2015), mostram que o uso de energia no sector familiar moçambicano vem aumentando significativamente nos últimos anos devido ao crescimento populacional, aumento do 
índice de urbanização, renda, extensão da rede eléctrica, entre outros factores. A análise destes autores, mostra que até 2030 este sector ainda será responsável pela maior parte do consumo total de energia em Moçambique. De modo geral, as estatísticas nacionais indicam que a matriz energética moçambicana é composta por uma mistura de fontes de energia que abastecem o sector doméstico, tais como, electricidade, LPG, lenha, carvão vegetal, querosene, velas, pilhas, gerador, baterias e a solar, que visam à satisfação das necessidades de iluminação, coacção, equipamentos electrónicos e mais (Arthur et al., 2011; Burgsdorff, 2017; Manuel e Victorino, 2020a, b).

Neste sentido, a gestão adequada do pacote energético disponível no país, passa necessariamente por um entendimento claro dos padrões de uso doméstico deste insumo, para promover a conservação e a gestão de energia por um lado e contribuir para o planeamento de acções futuras de gerenciamento, tanto do lado da oferta quanto da demanda por outro lado. De facto, nota-se que padrões de uso energético não só são relevantes para os processos de desenvolvimento económico, mas também afectam a qualidade de vida das famílias de forma imediata.

Parte do problema (até recentemente) tem sido a falta de dados sobre procura e demanda de energia no país em geral e na Cidade da Beira em particular. Dos poucos estudos realizados, identificamos o estudo realizado por Arthur et al. (2012), em nível nacional e, Deus (2014), na Cidade de Chimoio, o qual analisa o consumo de madeira para fins de energia doméstica, tendo concluído que as famílias da Cidade de Chimoio consomem em média mais carvão vegetal e lenha por dia e ano em relação as Cidades de Beira e Nampula. Em nível internacional, são vários estudos que foram e que têm sido desenvolvidos no que se refere a temática dos padrões de consumo doméstico de energia, por exemplo, destaca-se estudos de Eberhard (1990), na África do Sul, Hansen (2000), no município brasileiro de Porto Alegre, Tso e Yau (2003), em Hong Kong, Luz (2014), em Portugal, Ofetotse et al. (2015), no Botswana, França (2017), no Município de Porto Velho, estado brasileiro de Rondônia, Ateba et al. (2018), na África do Sul.

Do acima exposto depreende-se que a temática dos padrões de consumo doméstico de energia é um assunto complexo e desafiante, pois, a todo o momento, o consumidor é confrontado com vários produtos a serem confeccionados, novos tipos de aparelhos electrónicos que prometem conforto, rapidez para as actividades do dia-a-dia e outras facilidades da vida moderna altamente relacionada com as características físicas das residências e o comportamento dos usuários, que segundo Zhang et al. (2012); Fournier e Penteado (2010) torna o sector energético de muito interesse para os pesquisadores.

Para melhor compreensão, este artigo define o uso de energia directa como o uso de energia pelas famílias em suas casas (biomassa, electricidade, gás natural/GLP, carvão vegetal, querosene, pilhas, velas e outros tipos de energias) para cozinha, iluminação, electrodomésticos, aquecimento de água, refrigeração e lazer.

Tendo em vista que padrões de consumo doméstico de energia referem-se à maneira particular como os cidadãos de uma certa região utilizam determinadas fontes de energia para satisfação das suas necessidades energéticas, este artigo apresenta e analisa resultados de um estudo de caso com objectivo de compreender as dinâmicas envolvidas no uso directo de energia nos residentes do $14^{\circ}$ Bairro (Nhaconjo), na Cidade da Beira, no centro de Moçambique. Buscando, deste modo, responder as seguintes questões: Que tipo de fontes de combustíveis são usados pelos residentes do Bairro Nhaconjo? Em que serviços são aplicados tais combustíveis? Quem adquire ou efectua a compra dos combustíveis? Que tipo de equipamentos são empregues no uso de energia (para cozinhar, iluminar e aquecer água)? Onde cozinha? Quantas vezes cozinha? Que quantidade de combustíveis são usadas por cada agregado familiar? Qual é o combustível mais preferido/usado pelas famílias? 


\section{Materiais e métodos}

O presente estudo foi realizado na Cidade da Beira, no Centro de Moçambique, mais precisamente no 14을 Bairro denominado Nhaconjo, que se localiza ao longo da Estrada Nacional no 6 (EN6) e compõe o Posto Administrativo de Inhamizua (no 3). 0 bairro conta com uma população estimada em 35.882 habitantes (17.679 homens e 18.203 mulheres), distribuídos por cerca de 7.805 agregados familiares, habitando em 7.639 casas (INE, 2017). Segundo a Secretaria do 14o Bairro (2019), ele é composto por 36 quarteirões. Khan (2017) citando dados do INE (2012), mostra que este bairro é constituído por várias etnias, com predomínio das Ndau e Sena.

A área de estudo em causa é limitada ao norte pelos Bairros Vila Massane e Mungassa, ao sul pelo Bairro Alto da Manga, a este pelo Bairro Ndunda e a oeste pelo Bairro de Inhamizua (Figura 1).

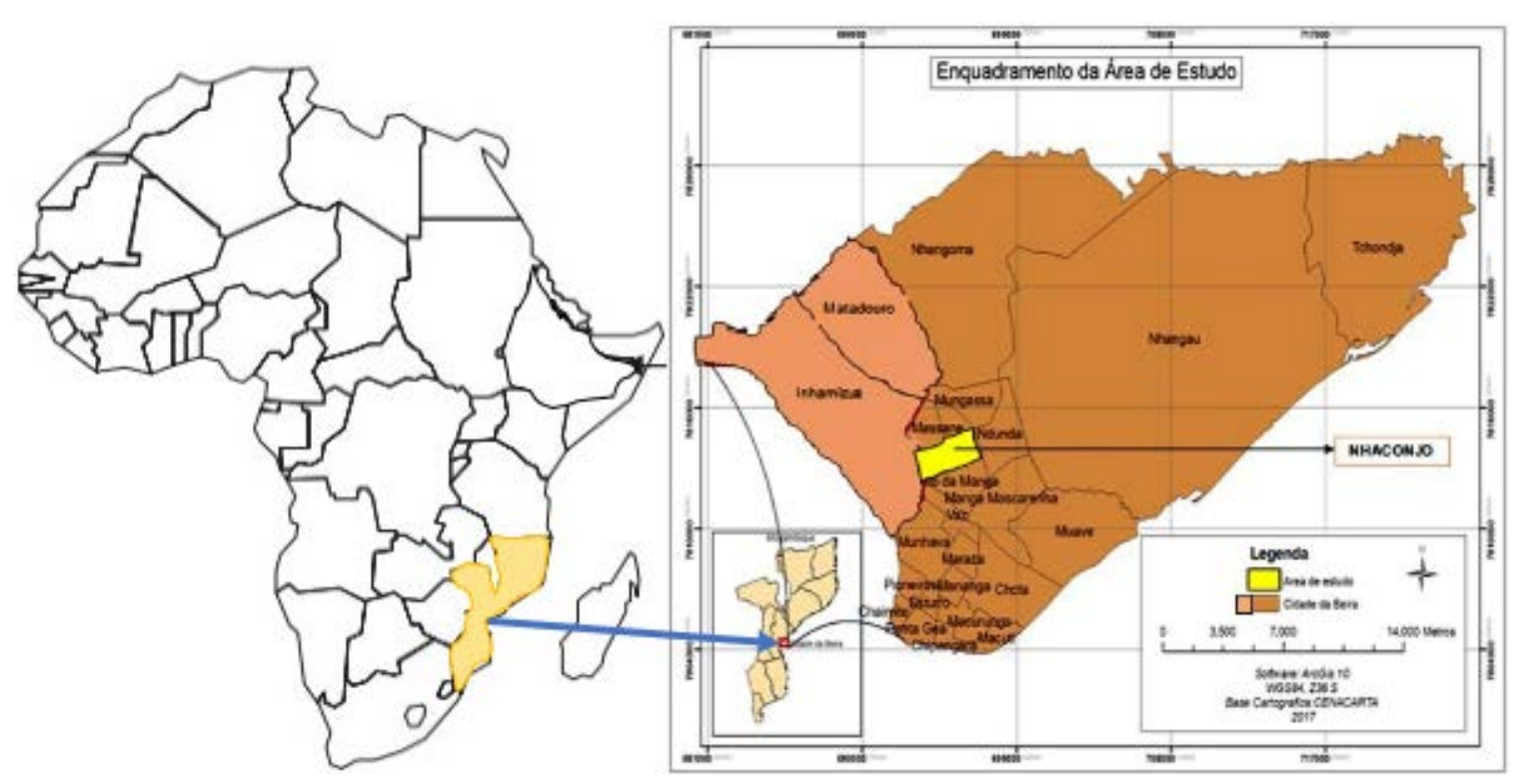

Figura 1. Enquadramento geográfico da área de estudo. Fonte: Adaptado de CENACARTA (2017).

A escolha da área foi motivada principalmente por suas características acentuadamente residenciais e, por apresentar diferentes tipos de residências ocupadas por classes sociais bastante diferenciadas, isto é, desde as casas ocupadas por uma população de baixa renda até áreas de mansões ocupadas por uma população de alto poder aquisitivo. Portanto, estas características nos pareceram, numa primeira análise, servir para a colecta de uma amostra bastante representativa para análise e estudo visando aos propósitos desta pesquisa.

Quanto aos métodos, foi utilizada, primeiramente, uma pesquisa bibliográfica e documental com a finalidade de identificar o estado da arte sobre o tema.

Para o cálculo do tamanho de amostra, considerou-se o mesmo método utilizado nos casos de amostragem probabilista com base na escolha aleatória simples e por conglomerados, usando a equação 1 (Marconi e Lakatos, 1999; Gil, 2008; Tódero, 2009; Deus, 2014): 


$$
\mathrm{n}=\frac{\mathrm{Z}^{2} * \mathrm{~N} * \widehat{\mathrm{p}} \cdot \widehat{\mathrm{q}}}{\mathrm{e}^{2} *(\mathrm{~N}-1)+\mathrm{Z}^{2} * \widehat{\mathrm{p}} \cdot \widehat{\mathrm{q}}}
$$

Onde:

Z: Valor padronizado. Para este parâmetro adoptamos o nível de confiança de 95\% $(1,96)$. $\mathrm{n}$ : Tamanho da amostra.

$\mathrm{N}$ : Universo de pesquisa que neste estudo compreende 7,805 agregados familiares $\hat{\mathrm{p}}$ : A proporção de inqueridos que dá informações de interesse neste estudo é de $50 \%$ $(0,5)$.

qิ : (100-p), proporção que não fornece informações de interesse neste estudo é de $50 \%$ $(0,5)$.

e: Erro amostral. 0 erro amostral recomendado é de 5\%.

Com o erro amostral recomendado (5\%) o tamanho da amostra calculado por meio da equação 1, seria extremamente grande (380 agregados familiares). Para reduzir o tamanho da amostra e seguindo o procedimento proposto por Deus (2014), ajustamos o erro para 14\%, que resultou na extracção, na área de estudo, de uma amostra de 49 agregados familiares.

Para a colecta dos dados foi elaborado um inquérito por questionário, adaptado a partir do referencial metodológico de Eberhard (1990) e Deus (2014), o qual foi aplicado numa primeira fase a três pessoas como forma de pré-teste, e na fase final aos 49 agregados que constituem a amostra. 0 questionário utilizado foi concebido para obter informações sobre a temática dos padrões de uso de energia no sector residencial, questionando assuntos relacionados ao perfil dos inqueridos e sobre o uso de diferentes combustíveis por parte destes, mediante o consentimento prévio do inquirido do chefe/representante da família.

\section{Colecta e análise de dados}

A colecta de dados durante a pesquisa foi realizada por meio de visitas aos residentes da área de estudo. A Figura 2 ilustra os vários combustíveis energéticos utilizados de forma isolada ou combinada pelas famílias visitadas e inquiridas durante o estudo.

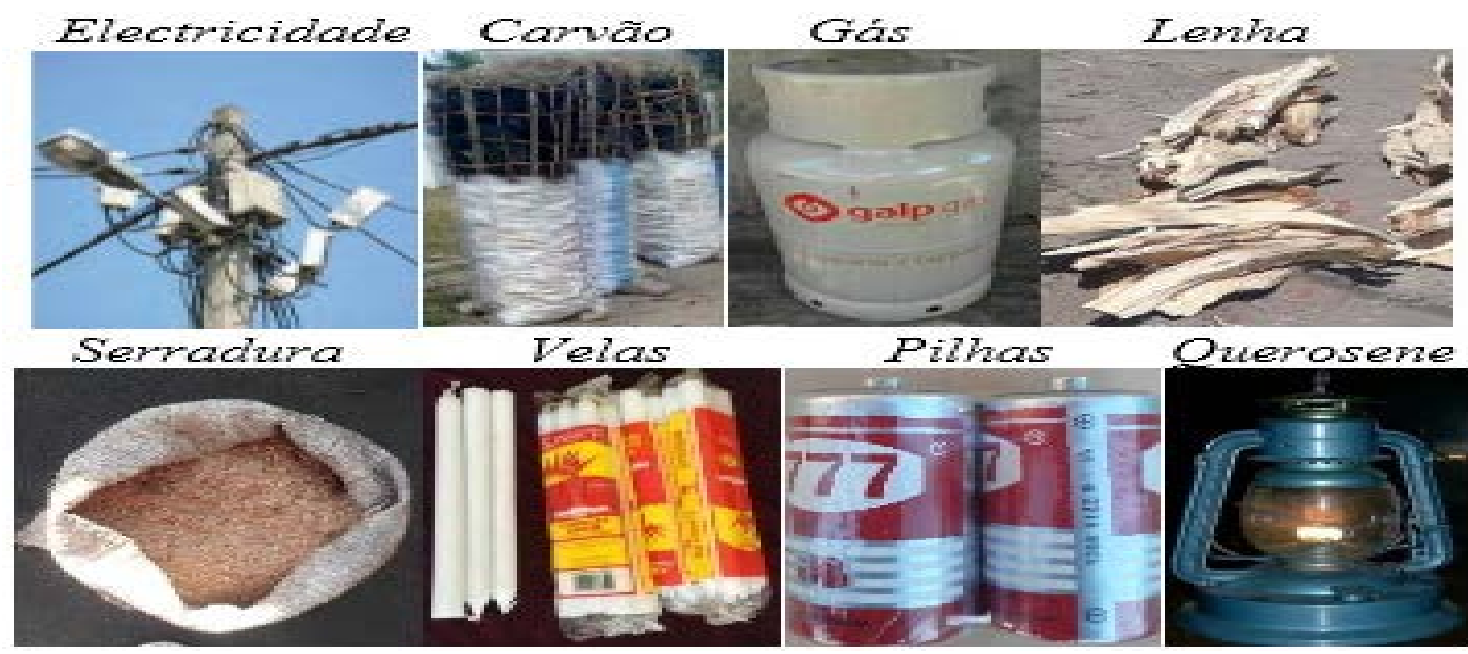

Figura 2. Fontes/combustíveis utilizados pelos agregados familiares. 
Para efeitos da pesquisa, a medição dos combustíveis sólidos tais como carvão, lenha, serradura e vela, relativos a estas famílias, usamos balanças indicadas na Figura 3 com capacidades de $22 \mathrm{~kg}, 50 \mathrm{~kg}$ e $300 \mathrm{~kg}$, respectivamente. As Figuras 4 e 5 mostram alguns momentos de pesagem dos combustíveis usados pelos moradores de Nhaconjo, analisados neste trabalho.
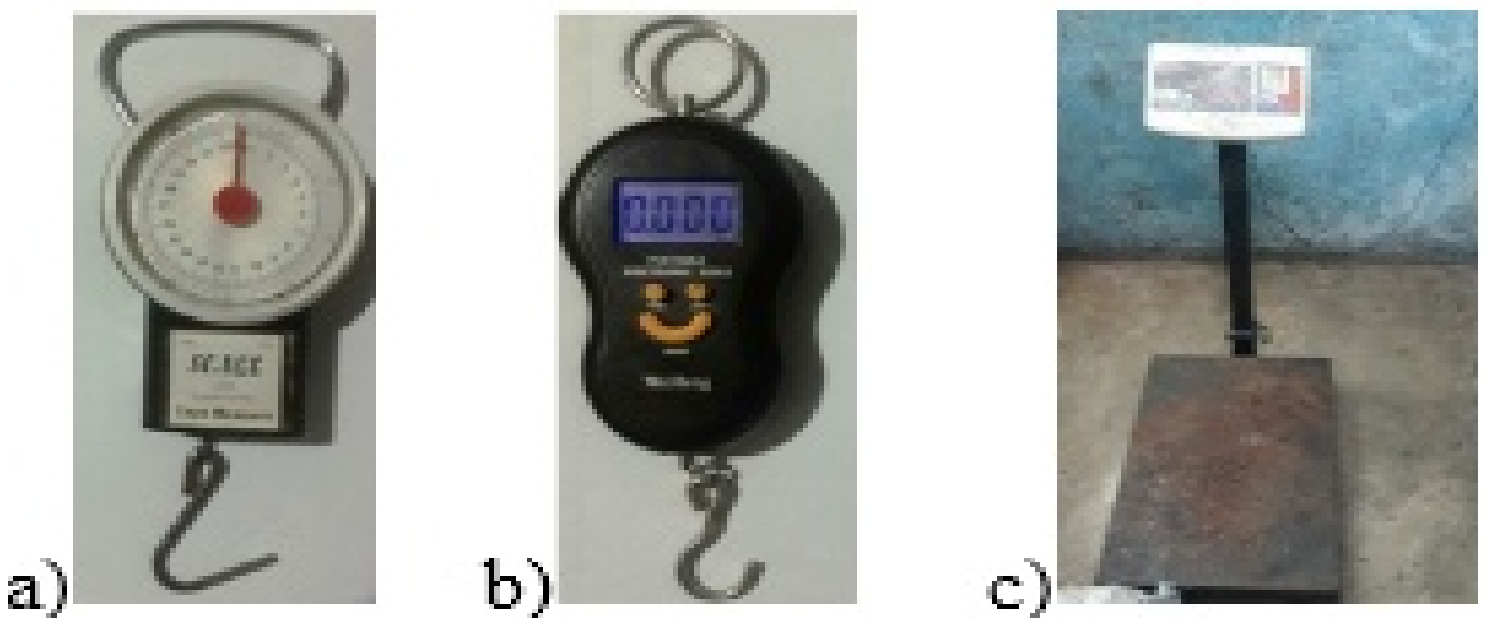

Figura 3. Instrumentos utilizados na medição de carvão, lenha e serradura.

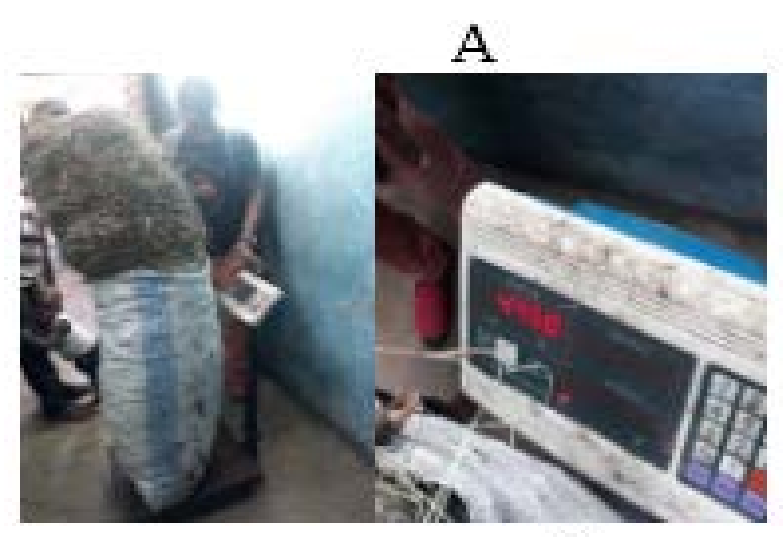

$\mathrm{C}$

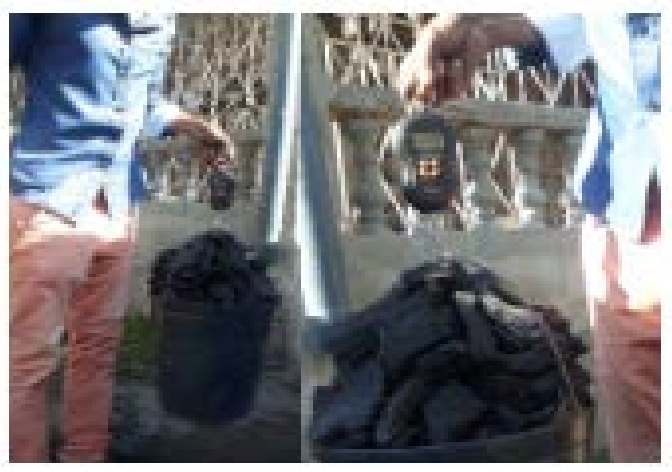

Figura 4. Quantificação do carvão vegetal.

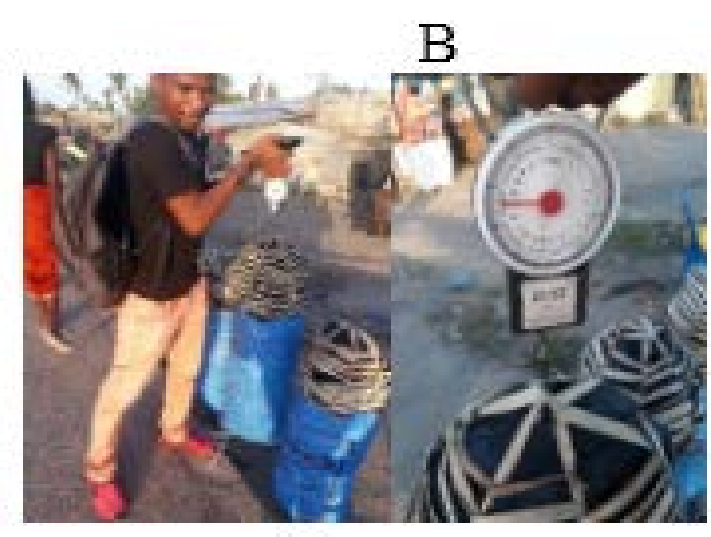

D

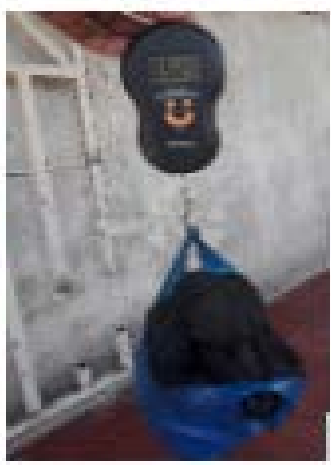




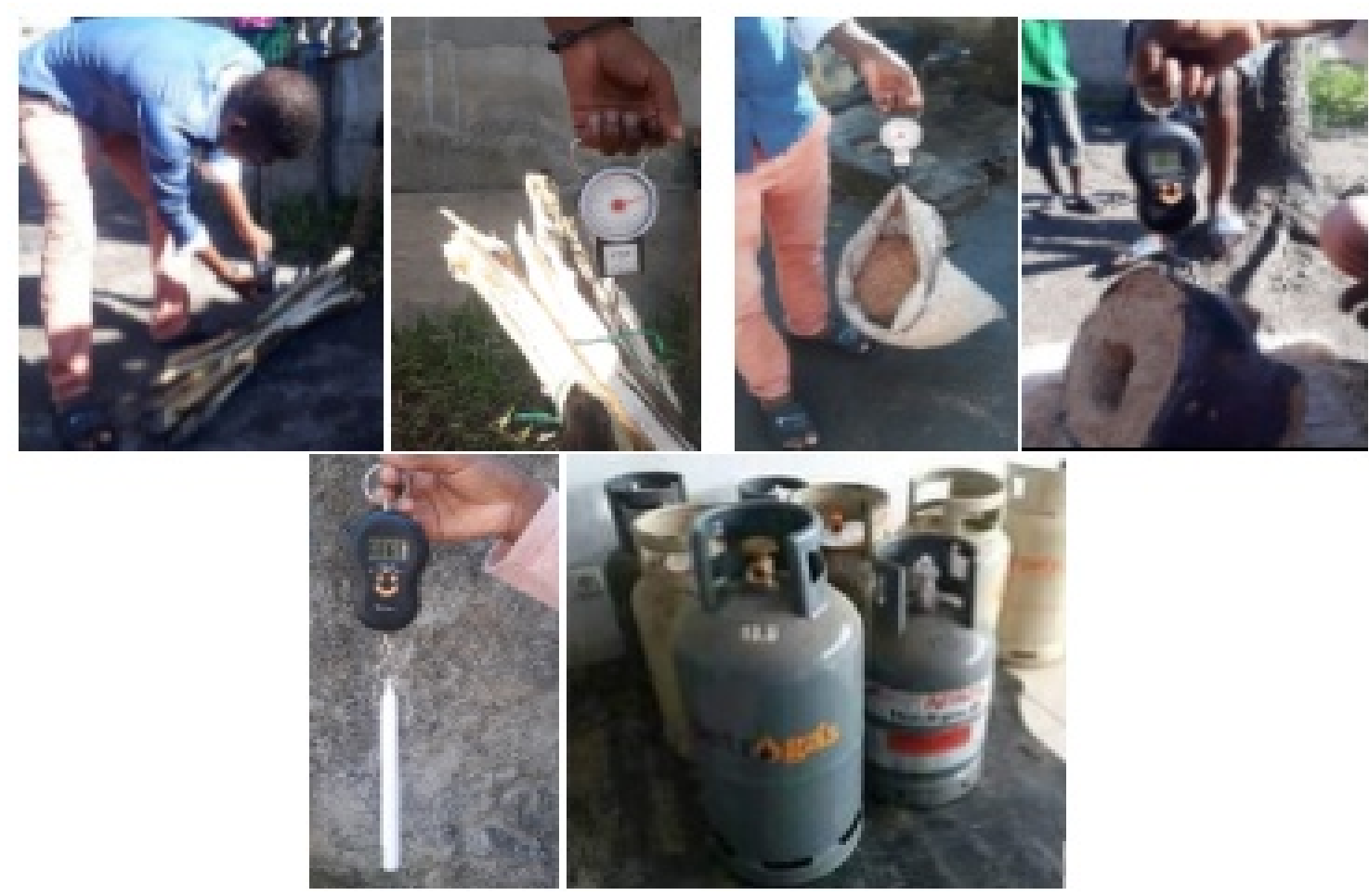

Figura 5. Quantificação de lenha, serradura, vela e gás.

A quantificação dos combustíveis como querosene e pilha foi com base na informação disponibilizada pelos agregados inquiridos. A quantidade de electricidade usada, foi obtida mediante dados fornecidos pela concessionária que presta serviços de distribuição da energia eléctrica no país, denominado Electricidade de Moçambique (EDM).

O consumo médio diário/semanal/mensal de cada domicílio analisado foi calculado através da média aritmética, usando a equação (2):

$$
\overline{\mathrm{X}}=\frac{X_{1}+X_{2}+X_{3} \ldots+X_{n}}{n}
$$

Onde:

$\overline{\mathrm{X}}$ : Média aritmética;

$\mathrm{X}_{1}, \mathrm{X}_{2}, \ldots \mathrm{X}_{\mathrm{n}}$ : Medidas efectuadas;

$n$ : Número de medidas efectuadas.

O consumo per capita dos combustíveis foi calculado através da equação (3):

$$
P I B_{p c}=\frac{\text { Quantidade de consumo anual do combustivel }}{\mathrm{N}^{\circ} \text { total dos inqueridos }}
$$


Para efeitos de uniformização a quantidade de energia usada por cada um dos agregados analisados foi expressa em Joule (e suas derivações (KJ: kilojoule e MJ: Megajoule) como medida padrão. Usando esta equação: $\left.Q_{C}=m * P_{C}\right)$, usando os poderes caloríficos e as seguintes relações:

- $1 \mathrm{kcal}=4,18 \mathrm{~kJ}$

- $1 \mathrm{~V}=1,6 \times 10^{-19} \mathrm{~J}$

Os valores caloríficos brutos são de $860 \mathrm{kcal} / \mathrm{kWh}$ para energia eléctrica, $5.000 \mathrm{kca} / \mathrm{kg}$ para carvão vegetal, $11.500 \mathrm{kcal} / \mathrm{kg}$ para o GLP, $2.900 \mathrm{kcal} / \mathrm{kg}$ para lenha seca ao ar (15\% de humidade), $3.330 \mathrm{kcal} / \mathrm{kg}$ para lenha mista (serradura), os derivados de petróleo (querosene, parafina e vela) variam de $10.000 \mathrm{kcal} / \mathrm{kg}$ (GASMIG, 2019).

A análise dos dados colectados foi realizada utilizando programas estatístico de computador (Microsoft Excel) e Word 2016, no sistema operacional Windows 7. E de seguida, esses dados foram tabulados, apresentados em forma de gráficos de coluna, circular ou linha e analisados com base nas respostas dos questionários de forma percentual para cada questão.

\section{Resultados}

\section{Perfil dos inqueridos}

Os resultados obtidos revelam que tanto os chefes de família quanto aqueles que não são chefes de agregados familiares participaram na resposta a questionários de pesquisa. Também é evidente a partir dos achados (Tabela 1) que a amostra do estudo é composta por agregados familiares chefiados por homens e chefiados por mulheres, embora a primeira constitua a maioria. A faixa etária predominante é de 31 a 40 anos, com $43 \%$ (Tabela 1).

Tabela 1. Género dos inqueridos e dos chefes de agregados familiares.

\begin{tabular}{|l|c|c|c|}
\hline Inqueridos & $\mathbf{\%}$ & Chefes de Agregados Familiares & $\mathbf{\%}$ \\
\hline Homens & 43 & Homens & 86 \\
\hline Mulheres & 57 & Mulheres & 14 \\
\hline Total & 100 & & 100 \\
\hline
\end{tabular}

Com base na tabela acima, nota-se que o estudo alcançou um desequilíbrio de género. 0 número dos inqueridos das mulheres é significativamente superior aos dos homens. Isso deve-se ao facto de que são as mulheres que se encontravam mais disponíveis para responder às questões propostas.

Quanto ao número de pessoas que vivem na residência, os resultados obtidos sugerem que, em média, a maior parte dos agregados são constituídos por 5 a 6 pessoas. Após questionados sobre a escolaridade, identificou-se que $29 \%$ dos agregados familiares tem Ensino Primário, 28\% possuem Ensino Secundário, 19\% Ensino Superior, 15\% Ensino Médio e apenas 9\% não tem instrução. No que se refere à ocupação laboral, dos 49 agregados familiares inqueridos a maioria afirma que possui profissão ou uma ocupação laboral que lhe dá um rendimento que possa sustentar o seu agregado familiar no final do mês. Com relação as condições de habitação (Tabela 2), a maioria dos inqueridos reside em habitações do T3 (39\% do total). As construções são na sua maioria de blocos (90\%). Quanto a cobertura, 51\% das casas estão cobertas de chapa de zinco, seguida de $43 \%$ de 
lusalite. Quanto ao tipo de aquisição das habitações, $67 \%$ das famílias têm a casa própria/construída e 18\% têm a casa alugada.

Tabela 2. Classificação das residências.

\begin{tabular}{|c|c|c|c|c|c|c|c|}
\hline Tipo & № & $\begin{array}{l}\text { Material de } \\
\text { construção }\end{array}$ & № & $\begin{array}{c}\text { Material de } \\
\text { cobertura }\end{array}$ & № & $\begin{array}{c}\text { Tipo de } \\
\text { aquisição da } \\
\text { casa }\end{array}$ & № \\
\hline $\mathrm{T} 1$ & 12 & Blocos & 44 & Chapa de zinco & 25 & Alugada & 9 \\
\hline $\mathrm{T} 2$ & 14 & Tijolos & 1 & Lusalite & 21 & Comprada & 3 \\
\hline T3 & 19 & \multirow{2}{*}{$\begin{array}{c}\text { Pau a pique } \\
\text { maticado }\end{array}$} & \multirow{2}{*}{4} & Betão & 3 & Construída & 33 \\
\hline $\mathrm{T} 4$ & 1 & & & & & Do serviço & 4 \\
\hline Flat & 3 & & & & & & \\
\hline Total & & & & 49 & & & \\
\hline
\end{tabular}

\section{Padrões de consumo doméstico de energia na área de estudo}

Os tipos de combustíveis encontrados na área de estudo e suas possíveis aplicações são mostrados na Tabela 3.

Tabela 3. Relação de fontes de energia e serviços energéticos que oferecem.

\begin{tabular}{|c|c|c|c|c|c|}
\hline \multirow{2}{*}{ Combustível } & \multicolumn{5}{|c|}{ Aplicações energéticas } \\
\hline & Cozinhar & Iluminação & Ferver água & Serviços gerais* & Churrasco \\
\hline Electricidade & $\mathrm{x}$ & $\mathrm{x}$ & $\mathrm{x}$ & $\mathrm{x}$ & \\
\hline Carvão vegetal & $\mathrm{x}$ & & $\mathrm{x}$ & & $\mathrm{x}$ \\
\hline GLP & $\mathrm{x}$ & & & & \\
\hline Lenha & $\mathrm{x}$ & & $\mathrm{x}$ & & $\mathrm{x}$ \\
\hline Serradura & $\mathrm{x}$ & & $\mathrm{x}$ & & \\
\hline Querosene & & $\mathrm{x}$ & & & \\
\hline Vela & & $\mathrm{x}$ & & & \\
\hline Solar e pilha & & $\mathrm{x}$ & & $\mathrm{x}$ & \\
\hline
\end{tabular}

*Refrigeração, aparelhos/entretenimento, ferro eléctrico, máquina de lavar roupa, microondas, condicionamento ambiental, entre outros (liquidificador, batedeira, aspirador de pó, etc.).

No entanto, a disponibilidade de combustíveis declarada pelos inqueridos sugere que: a electricidade, o carvão, querosene, vela e pilhas estão prontamente disponíveis; a lenha e serradura estão modestamente disponíveis; o GLP é muito escassamente disponível; enquanto a solar está virtualmente indisponível.

No geral, a maioria dos agregados familiares utiliza electricidade (100\%), seguida de carvão vegetal (92\%) (Figura 1). 


\section{COMBUSTÍVEIS USADOS NAS RESIDÊNCIAS}

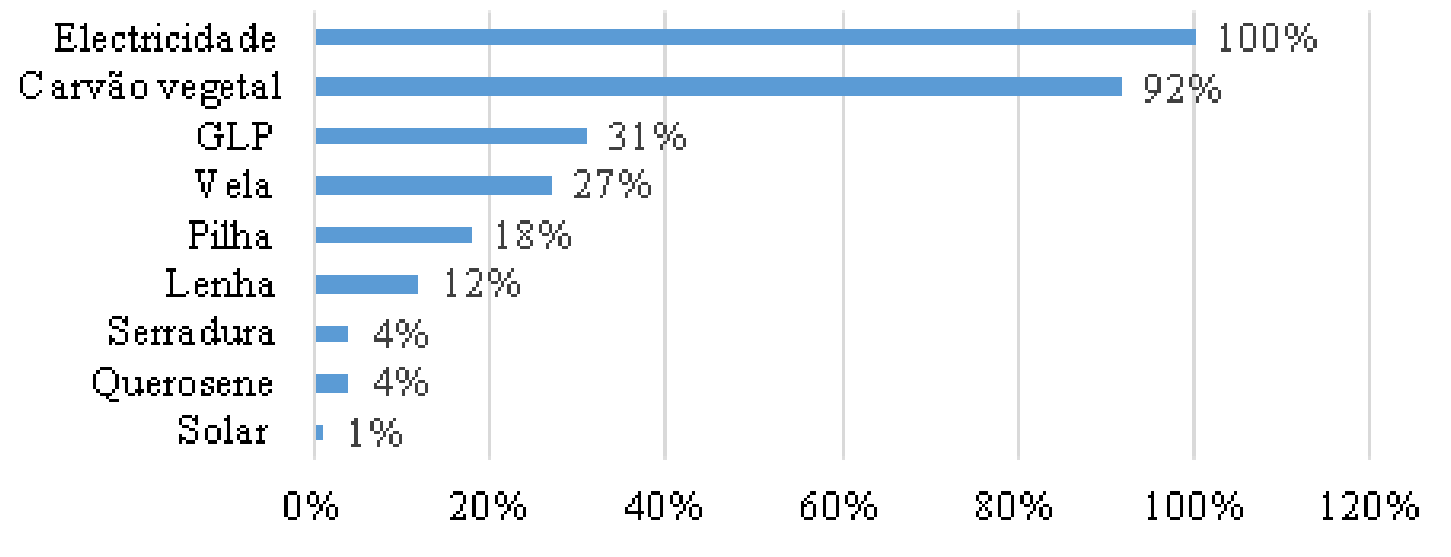

Figura 1. Percentagem de residências que utilizam várias fontes de energia na área de estudo.

Relativamente a aplicações energéticas, dos combustíveis usados para cozinha, o carvão é o único combustível isolado, isto é, as famílias fazem o uso deste combustível sem misturar com outros combustíveis. $\mathrm{Na}$ iluminação e serviços gerais destaca-se a electricidade como o combustível isolado; para o aquecimento de água encontram-se a electricidade e o carvão como combustíveis isolados. Mas também, esses combustíveis isolados são geralmente usados em conjunto com outros combustíveis. Várias observações podem ser deduzidas desta mistura de combustíveis nas Figuras 2, 3 e 4.

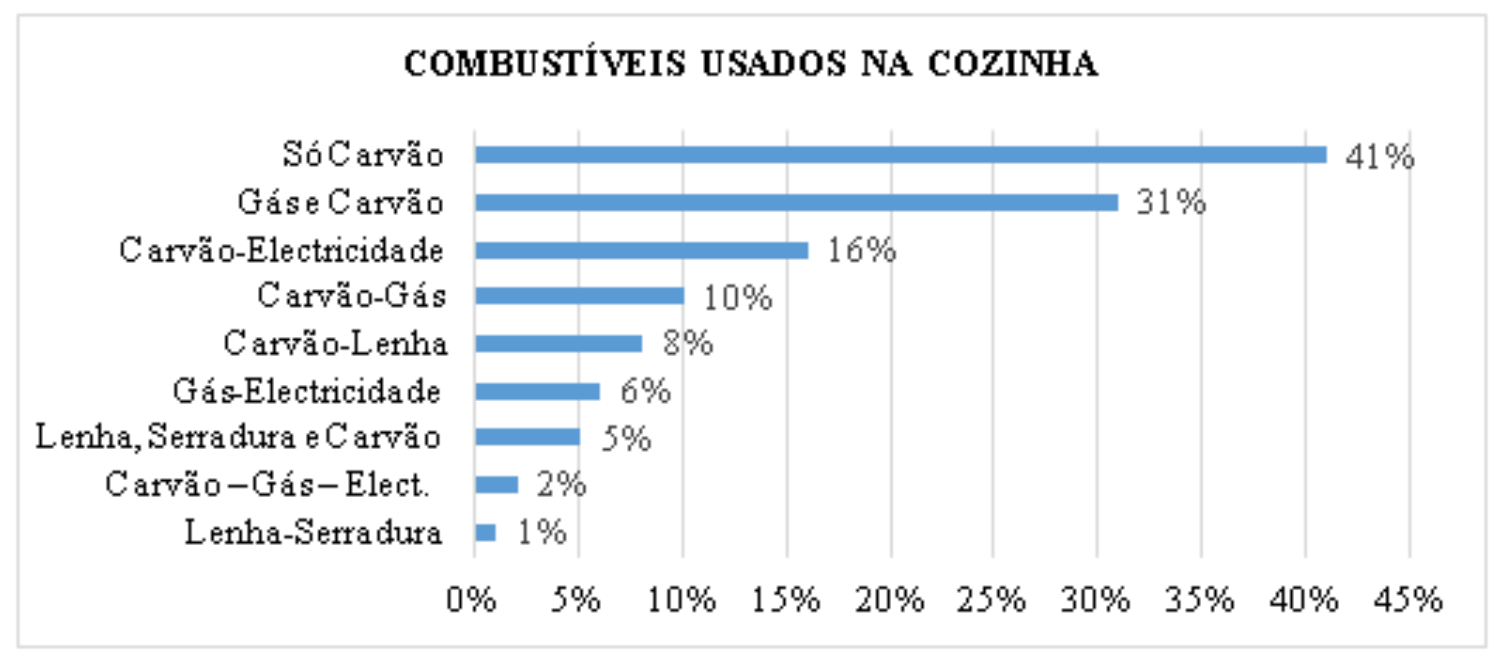

Figura 2. Percentagem dos combustíveis usados na cozinha pelas famílias inqueridas. 


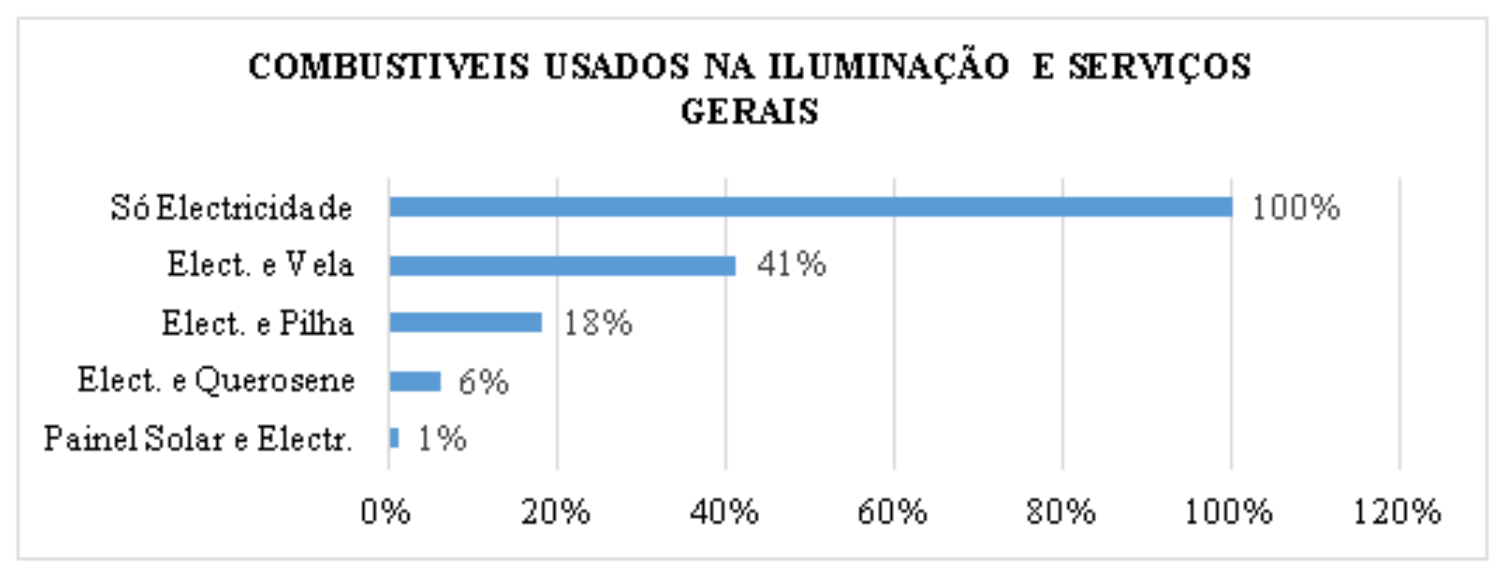

Figura 3. Percentagem dos combustíveis usados na iluminação e serviços gerais.

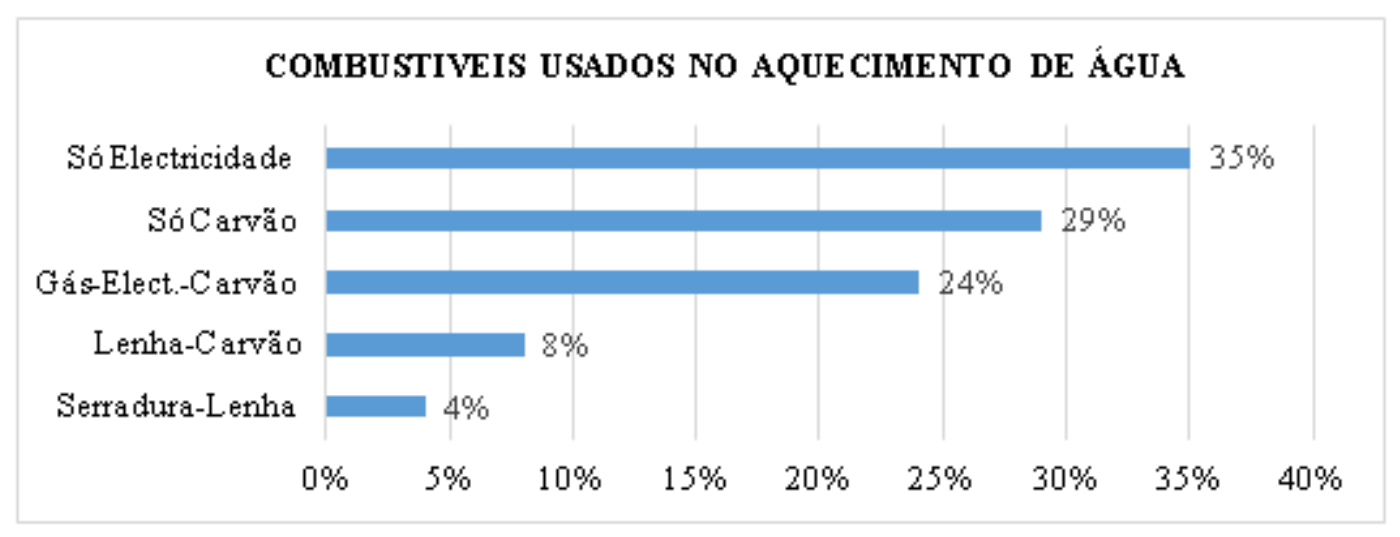

Figura 4. Percentagem dos combustíveis usados no aquecimento de água.

Com base nas figuras, pode-se afirmar que, no geral, as famílias usam mais de um tipo de combustível (mistura de combustíveis) para a satisfação das suas necessidades básicas.

A colecta e a compra dos combustíveis são na maioria dos casos feita por mulheres e crianças, efectuada em muitos casos por numerário/dinheiro (no caso de carvão e gás) e por colecta (no caso da lenha e serradura). Ao contrário da electricidade que na sua maioria são os homens que efectuam a compra, em muitos casos por via electrónica. No que se refere a velas, pilhas e querosene, a maior parte dos respondentes afirmam que a compra destes combustíveis depende em parte da situação, da necessidade e da disponibilidade da pessoa. 0 tempo gasto na busca dos combustíveis depende, em parte, da distância entre a residência e local de venda (mercado ou rua) e de colecta (oficina de serração de madeira, etc.).

Quanto ao equipamento usado na confecção dos alimentos, destaca-se o fogão, sendo a carvão vegetal (78\%), a gás (13\%), eléctrico (7\%) e por último encontra-se o fogão a lenha e a serradura com 1\%, respectivamente. Dos agregados inqueridos constatou-se que $97 \%$ cozinham no interior da casa (na cozinha ou na varanda). Sendo a iluminação fortemente dependente da electricidade, o uso de lâmpadas se faz presente em todas residências pesquisadas (100\%), coadjuvado com lanternas e candeeiros com $8 \%$ e $3 \%$, respectivamente (Figura 5 ). 


\section{EQUIPAMENT OS USADOS NA ILUMINAÇÄO}

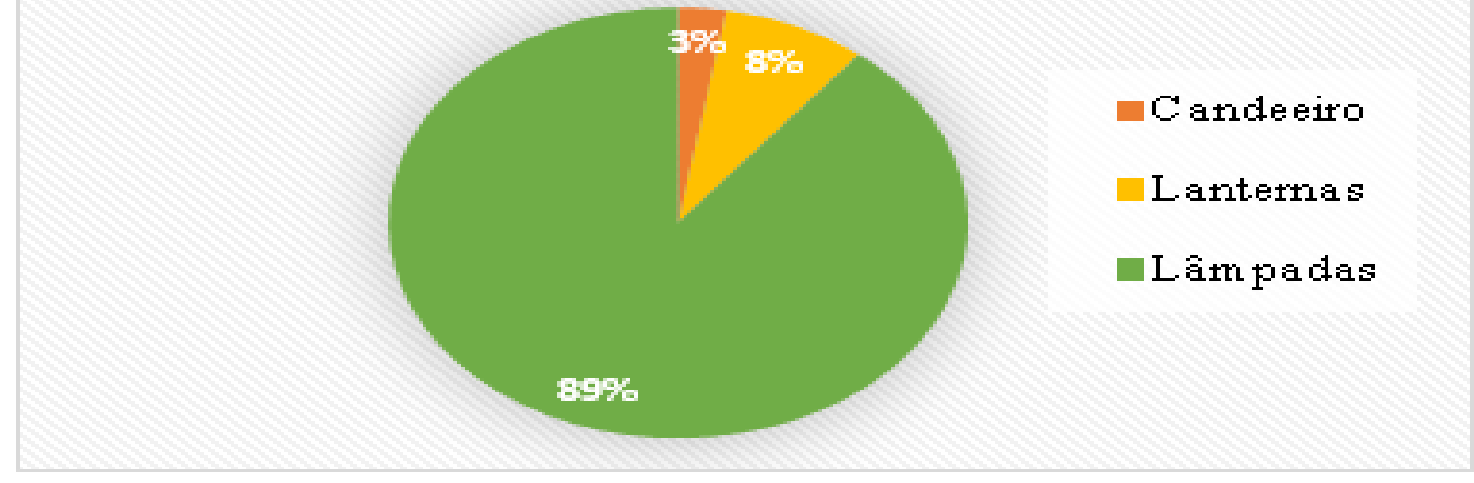

Figura 5. Equipamentos usados para a iluminação.

Em termos do total dos agregados inqueridos, um terço das famílias utilizam equipamentos electrónicos (fogão eléctrico e chaleira eléctrica) para o aquecimento de água, com uma parte considerável optando por fazer o uso de outros equipamentos (Figura 6).

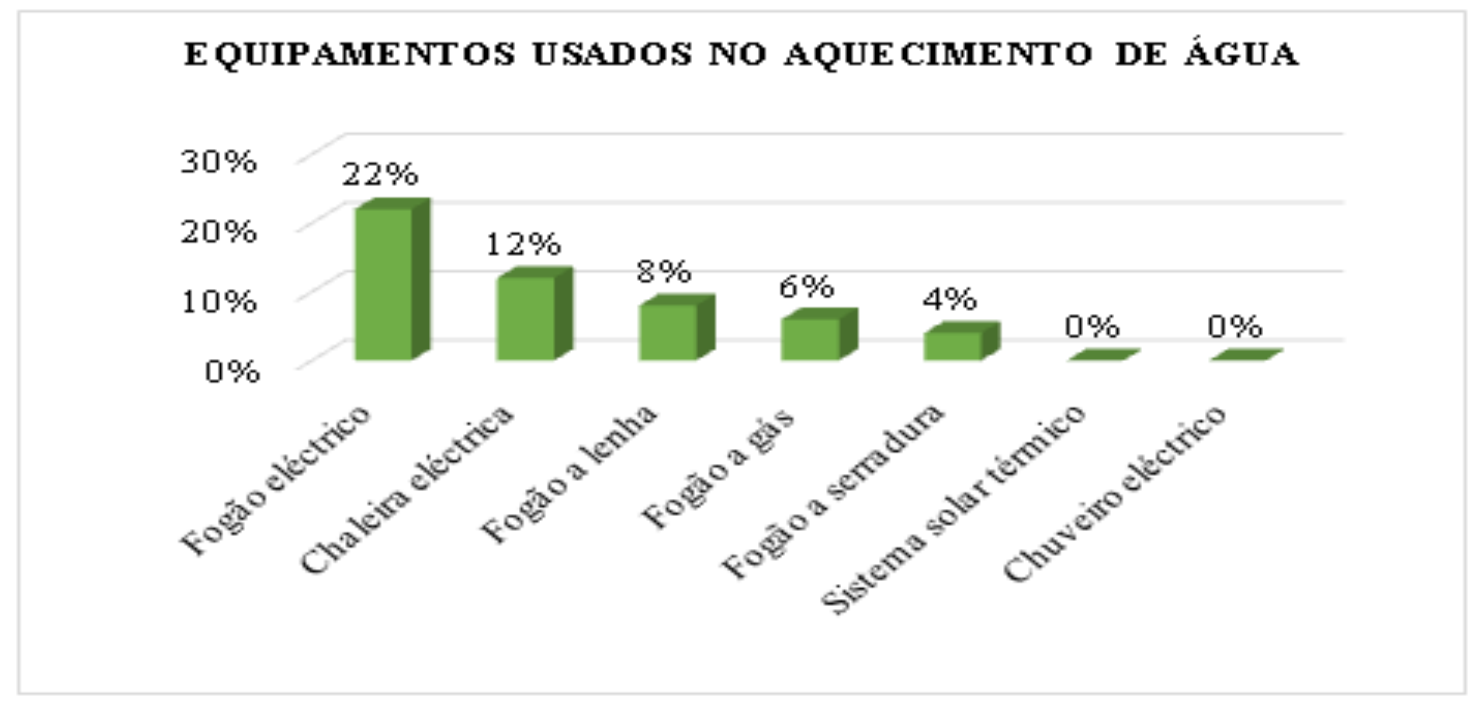

Figura 6. Equipamentos usados para aquecimento de água.

Quando questionados sobre o número de cozimento diário, constatou-se que em média $65 \%$ das famílias cozinham três vezes por dia (Figura 7). 


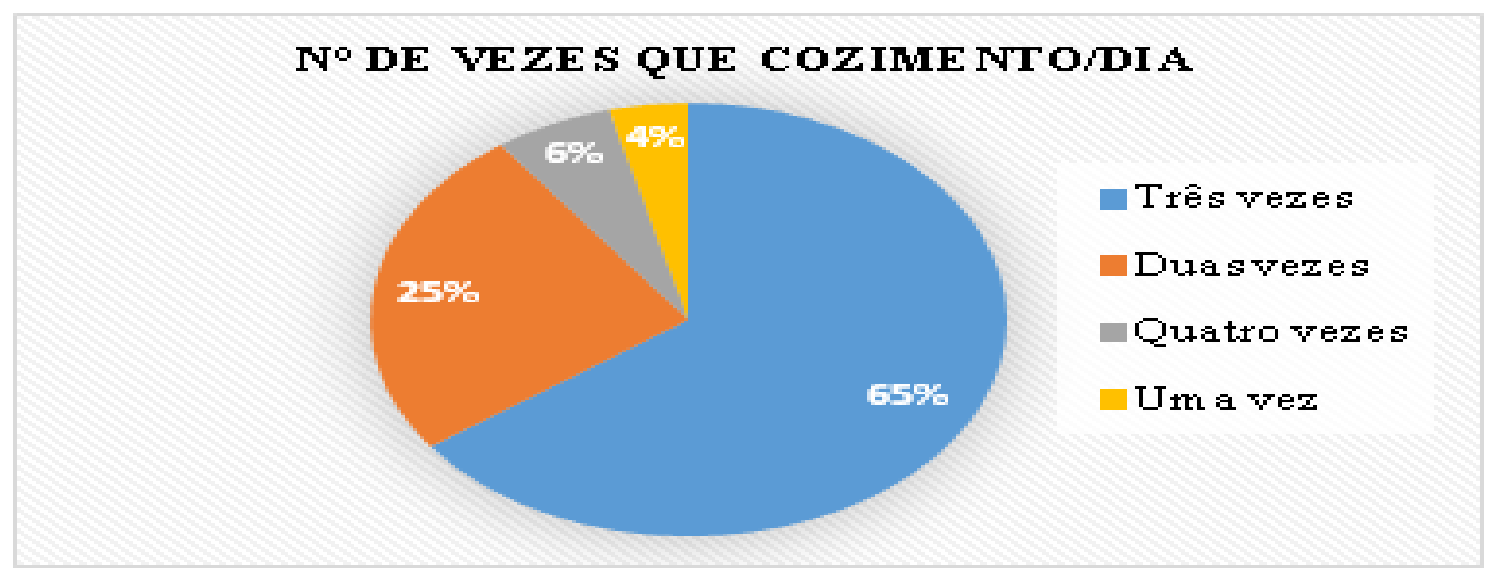

Figura 7. Opinião dos consumidores em relação ao número de cozimento.

\section{Quantidade dos combustíveis consumidos pelos agregados familiares}

Com as medições anteriormente efectuadas, as quantidades de carvão vegetal em média obtidas foram 44,5 kg para um saco de capacidade $50 \mathrm{~kg}$, cujo o custo varia entre 500 e $650 \mathrm{mt} ; 17,2 \mathrm{~kg}$ foi o peso de um saco de carvão de capacidade $25 \mathrm{~kg}$, com um custo que varia entre 220 e $300 \mathrm{mt}$; um balde contendo carvão, o seu peso foi 6,715 kg e o seu custo varia entre 100 e $150 \mathrm{mt}$. E, um plastiquinho que custa $10 \mathrm{mt}$ o peso foi de $0,525 \mathrm{~g}$. Um dado importante a salientar é que o peso do carvão vegetal depende em parte do tipo de madeira de que é produzido o carvão, podendo pesar mais ou menos. Em relação a lenha obteve-se $5 \mathrm{~kg}$ para um molho que custa $20 \mathrm{mt}$. Paralelamente ao carvão vegetal a lenha depende do tipo e da humidade da madeira. No caso da serradura mediu-se a quantidade colhida (em saco), cujo o peso foi de 7,9 kg e a quantidade contida no fogão, cujo o peso foi de 1,875 kg. Quanto ao gás (GLP) tomou-se a unidade do recipiente (botija) para estimativa do consumo mensal, com um custo que varia de $475 \mathrm{mt}$ (botija de $9 \mathrm{~kg}$ ), $650 \mathrm{mt}$ (botija de $11 \mathrm{~kg}$ ), $695 \mathrm{mt}$ (botija de $12 \mathrm{~kg}$ ) e $1.089 \mathrm{mt}$ (botija de $13 \mathrm{~kg}$ ).

Com base nas respostas dos questionários constatou-se que os inqueridos usam num mês um total de 17 velas, 18 pilhas ( $27 \mathrm{~V} /$ mês). E uma vela que custa $15 \mathrm{mt}$ o seu peso foi de 0,065 kg (1.105 kg/mês). A quantidade do consumo médio mensal, diário, anual e per capita dos combustíveis usados pelos agregados familiares pesquisados foi estimada como mostrado na Tabela 4.

Tabela 4. Consumo doméstico médio mensal, diário, anual e per capita de energia.

\begin{tabular}{|l|c|c|c|c|c|c|c|c|}
\hline \multicolumn{1}{|c|}{ Combustíveis } & Electricidade & Carvão & GLP & Lenha & Serradura & Querosene & Vela & Pilha \\
\hline Unidade & $\mathrm{kWh}$ & $\mathrm{kg}$ & $\mathrm{kg}$ & $\mathrm{kg}$ & $\mathrm{kg}$ & $1 \mathrm{~L}=1 \mathrm{~kg}$ & - & $\mathrm{V}$ \\
\hline Quantidade/mês & $1.815,1$ & $1.722,3$ & 167 & 140 & 15,8 & 1,5 & 17 & 27 \\
\hline $\begin{array}{l}\text { Consumo médio } \\
\text { mensal }\end{array}$ & 60,5 & 57,4 & 11 & 23 & 7,9 & 0,75 & 1,105 & 3 \\
\hline $\begin{array}{l}\text { Consumo médio } \\
\text { diário }\end{array}$ & 2 & 1,9 & 0,366 & 4,96 & 1,875 & - & - & - \\
\hline Quantidade/ano & 21.781 & 20.668 & 60.955 & 1.680 & 189,6 & 18 & 204 & 324 \\
\hline $\begin{array}{l}\text { Consumo médio } \\
\text { per capita }\end{array}$ & 444,5 & 421,8 & 40,9 & 34,3 & 3,9 & 0,37 & 4 & 4,4 \\
\hline
\end{tabular}


Os dados de consumo médio mensal foram convertidos em valores de energia equivalentes (Megajoule) para avaliar a contribuição proporcional de cada combustível líquido e útil, sendo a nergia líquida o total comprado pelo usuário e energia útil é a quantidade disponível a partir do aparelho de conversão para cozinhar ou aquecimento (Eberhard, 1990), no uso de energia (Figura 8).

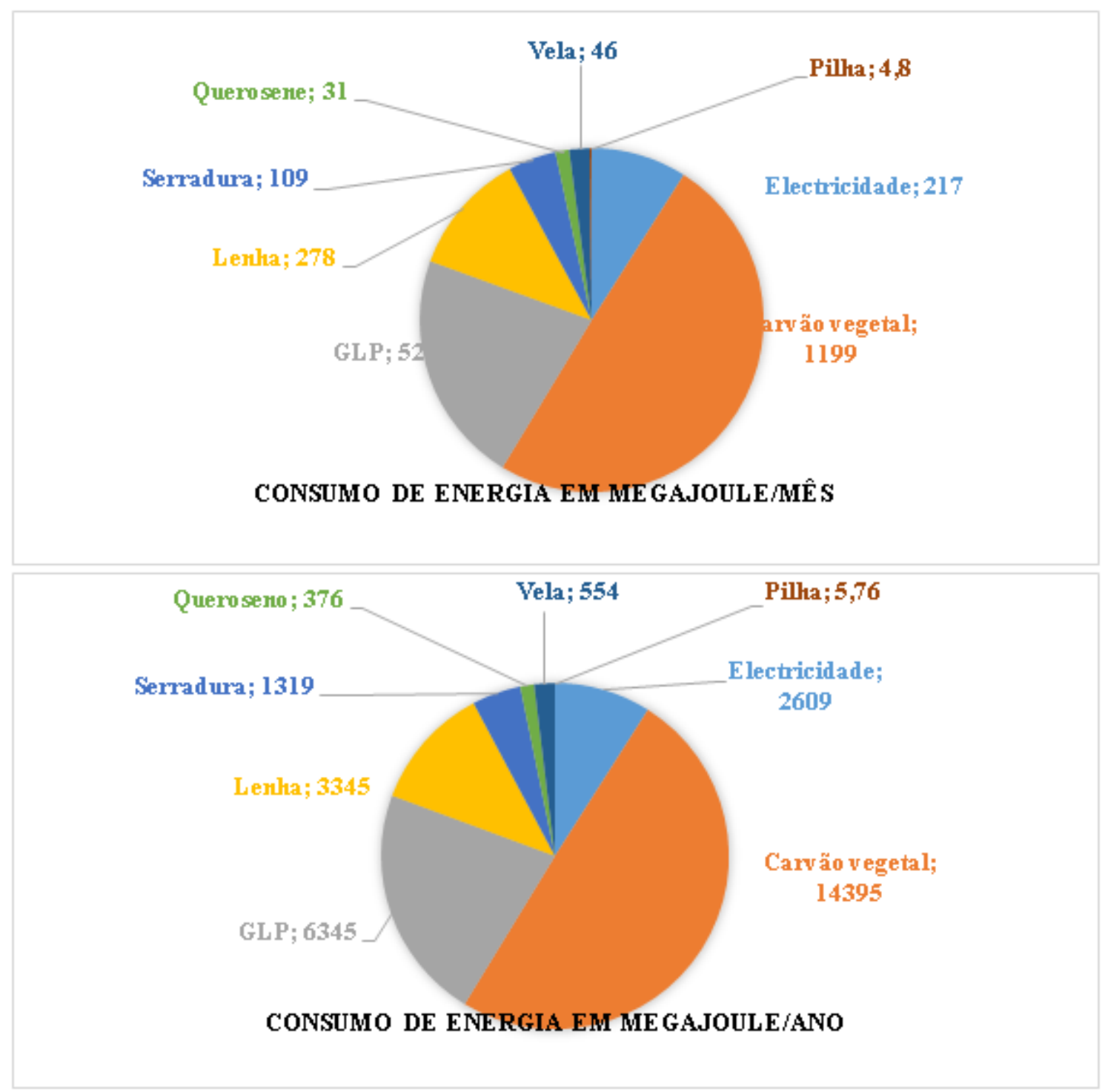

Figura 8. Consumo mensal e anual de energia útil em Megajoule (MJ).

\section{Preferências dos agregados familiares aos combustíveis}

Os inqueridos foram solicitados a indicar suas preferências acerca dos combustíveis por eles usados para a satisfazer as suas necessidades diárias assim como cerimoniais. Os resultados apresentados indicam que a maioria dos inqueridos (98\%) preferem a electricidade e o carvão vegetal (Figura 9). 


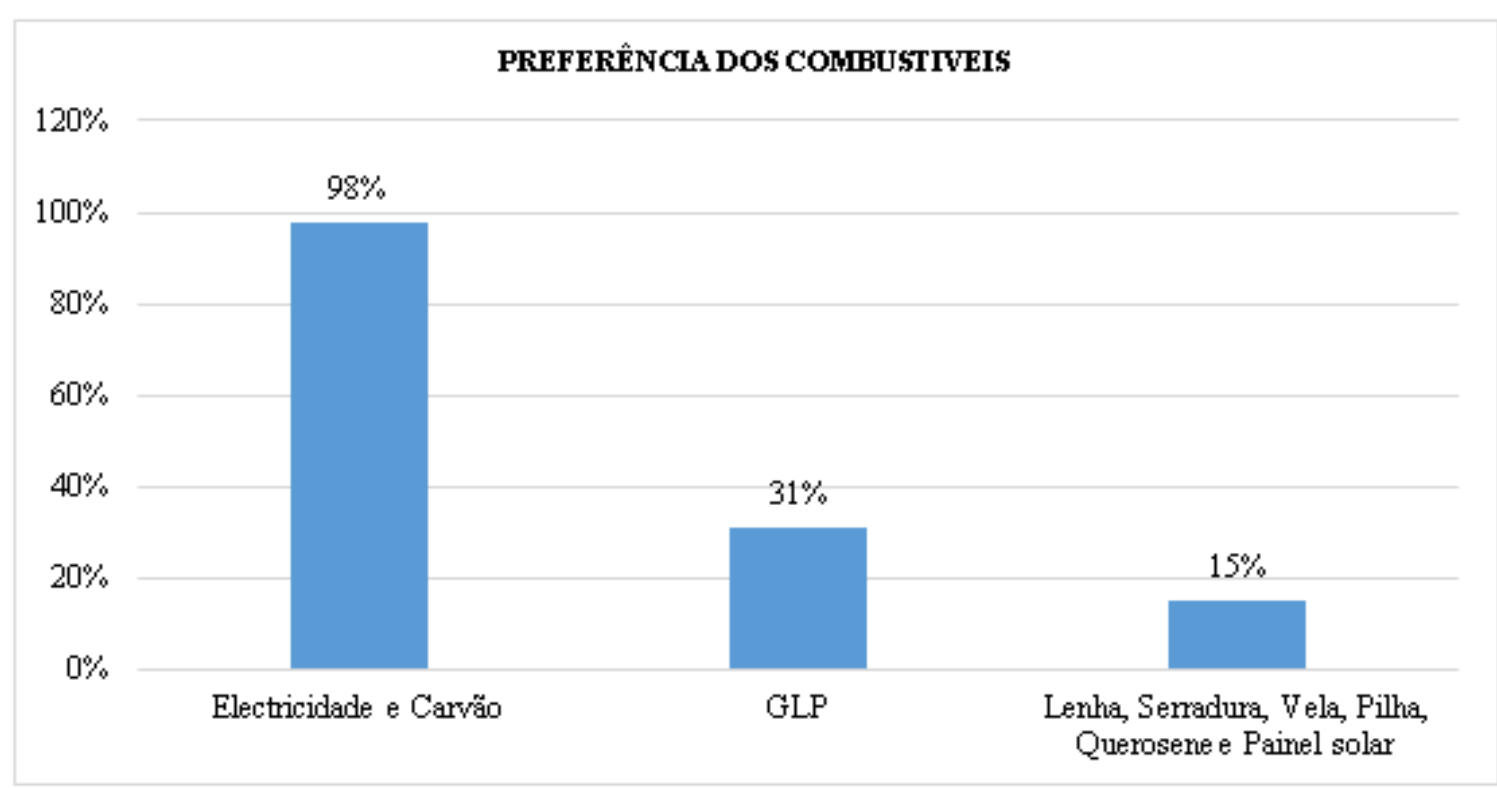

Figura 9. Combustíveis mais preferidos pelos agregados familiares.

Em última instância, os inqueridos foram capazes de dar razões da sua preferência, que na sua maioria afirmam que a electricidade oferece boa iluminação, adequada, viável e acessível, pois, através dela vê-se novelas e notícias, além disso facilita na realização de múltiplas actividades (cozinhar, iluminar, lazer). O carvão vegetal é apontado como combustível mais económico, de baixo custo (barato), fácil de adquirir e alguns acreditam (erroneamente) que é menos poluente e estão habituados a usá-lo, e além de ser usada para o cozimento, também, está intimamente relacionado com a sua utilização na preparação do churrasco ("assar carne", etc.).

A lenha e a serradura são menos preferidas por várias razões, primeiro, alguns associam a falta de condições para ter acesso a outras formas de energia, segundo por fazer muito fumo durante a confeição de alimentos, por poluir o meio, provocando várias doenças a mulheres que normalmente ficam expostas aos fumos provocados por este combustível, e também, por já não ser uma prática comum nas cidades. Apesar da evolução do uso do GLP que se tem verificado nos últimos tempos, alguns inquerido guiados pelos factores culturas, consideram este combustível de muito perigoso, outros alegam que o custo inicial de aquisição da botija que é bastante caro, pois, a maior parte deles afirmam não ter o poder de compra dos equipamentos (fogão e botija) para o uso deste tipo de combustível e, também, está em causa a acessibilidade do combustível.

No que se refere a querosene, vela, pilha e painel solar (em casos muito raro), segundo os inqueridos, só se recorre a estas formas de energia como parte de uma estratégia de substituição de electricidade em casos de interrupções de serviço de energia eléctrica ou se a família esgota suas despesas orçamentadas no caso dos contadores de electricidade pré-pagos.

\section{Discussão}

A evidência empírica do presente estudo revelou que os padrões de consumo doméstico de energia nos residentes do 14ํㅡㄹ Bairro da Cidade da Beira mostraram-se muito diferenciados, pois, a maior parte daquela população usa uma mistura de combustíveis domésticos, compostos por: electricidade, carvão vegetal, GLP, lenha, serradura, querosene, vela, pilha e solar, para a satisfação das suas necessidades. 
Dos combustíveis acima mencionados, os principais são a electricidade e o carvão vegetal. A electricidade é a principal forma de energia usada nas residências (100\%), para a iluminação e ligação de aparelhos electrónicos, para aquecimento de água (por exemplo, usando chaleiras ou aquecedores eléctricos) e para cozinhar (por exemplo, usando fogões eléctricos, fornos de micro-onda). Padrões semelhantes também foram encontrados no IOF (2015) e Silva (2017), na Cidade da Beira e Ateba et al., (2018), na África do Sul, nos quais faz-se menção que, na área urbana, aproximadamente $70 \%$ de agregados familiares tem a energia eléctrica como a principal fonte de iluminação e os restantes $30 \%$ utilizam outras fontes de iluminação (querosene, velas e lanternas) como segunda alternativa.

O carvão vegetal (usado por 92\%) é o combustível mais dominante para a confecção dos alimentos. Este resultado, também, é comprovado por Silva (2017), na Cidade da Beira e Deus (2014) na Cidade de Chimoio, ao mostram que para a confecção de alimentos, a fonte de energia mais utilizada é o carvão vegetal. 0 GLP, a lenha e a serradura são comumente usadas para cozinhar e para aquecer água.

A maioria das famílias (90\%) adquirem os seus combustíveis por via da compra, efectuada na maioria dos casos por mulheres e crianças. Essa observação é semelhante à de outros estudos, como por exemplo, o estudo de Lusambo (2016), na Tanzania, em que mulheres e crianças dedicam muito tempo e trabalho para reunir combustível e cozinhar alimentos para a família. Esta é a evidência de que as mulheres sofrem desproporcionalmente em caso de escassez de combustíveis.

O fogão a carvão é o equipamento mais utilizado na confecção dos alimentos (78\%), fogão eléctrico e chaleira eléctrica no aquecimento de água (34\%), as lâmpadas na iluminação (100\%). No que se refere ao esquecimento de água , um resultado diferente é apresentado por Achão (2003), ao afirmar que, no Brasil, os aparelhos mais comuns utilizados para essa actividade são os chuveiros eléctricos. Dos agregados inqueridos constatou-se que 97\% cozinham no interior da casa (na cozinha ou na varanda); em muitos casos três vezes por dia, o que demostra a consideração das três refeições tidas como básicas (pequeno almoço, almoço e jantar).

\section{Conclusões}

Esta pesquisa analisou o consumo de energia doméstica com foco especial nos padrões de consumo. Os resultados indicaram que a maioria dos agregados familiares depende de um mix de combustíveis para satisfazer as suas necessidades. E, em termos do consumo líquido de energia doméstica chegou-se as seguintes conclusões:

- A electricidade é mais utilizada pelas famílias (para iluminação e serviços gerais) com um total de $100 \%$, equivalente em média a $60 \mathrm{kWh} /$ mês por família, 2 $\mathrm{kWh}$ /dia com um consumo per capita estimado em $444,5 \mathrm{kWh}$ per capita. Cujo o consumo útil é de $217 \mathrm{MJ} /$ mês e $2.609 \mathrm{MJ} /$ ano.

- $\quad$ carvão vegetal é o combustível mais consumido na confecção dos alimentos, com um total de $92 \%$ das famílias, equivalente em média a 57,4 kg/mês por família, 1,9 $\mathrm{kg} /$ dia com um consumo per capita estimado em 421,8 kg. A forma mais comum de consumo de carvão vegetal é em sacos. Cujo o consumo útil é de $1.199 \mathrm{MJ} / \mathrm{mês}$ e 14.395 MJ/ano.

- $\quad$ GLP é consumido por um total de 31\% das famílias (média de $11 \mathrm{~kg} / \mathrm{mês}$ por família, $366 \mathrm{~g} /$ dia e 40,9 $\mathrm{kg}$ per capita). Cujo o consumo útil é de $528 \mathrm{MJ} / \mathrm{mês}$ e $6.345 \mathrm{MJ} /$ ano.

- A lenha é consumida por um total de $12 \%$ das famílias (média de $23 \mathrm{~kg} / \mathrm{mês}$ por família, 4,96 kg/dia e 34,3 kg per capita). Cujo o consumo útil é de $278 \mathrm{MJ} / \mathrm{mês}$ e $3.345 \mathrm{MJ} /$ ano. 
- A serradura é consumida por um total de $4 \%$ das famílias (média de $7,9 \mathrm{~kg} / \mathrm{mês}$ por família, 1,875 kg/dia e 3,9 kg per capita). Cujo o consumo útil é de $109 \mathrm{MJ} / \mathrm{mês}$ e $1.319 \mathrm{MJ} /$ ano.

- A querosene, também é consumida por um total de $4 \%$ das famílias (média de 0,75 L/mês por família e $0,37 \mathrm{~L}$ per capita). Cujo o consumo útil é de $31 \mathrm{MJ} /$ mês e 376 $\mathrm{MJ} /$ ano.

- A vela é consumida por um total de $27 \%$ das famílias (em média uma vela/mês por família e 4 velas per capita). Cujo o consumo útil é de $46 \mathrm{MJ} / \mathrm{mês}$ e $554 \mathrm{MJ} / \mathrm{ano}$.

- A pilha é consumida por um total de $18 \%$ das famílias (em média de $3 \mathrm{~V} /$ mês por família e 4,4 V per capita). Cujo o consumo útil é de $4.8 \times 10^{-13} \mathrm{MJ} / \mathrm{mês}$ e $5,76 \times 10^{-12}$ $\mathrm{MJ} / \mathrm{ano}$.

- Os combustíveis mais preferidos pelas famílias é a electricidade e o carvão vegetal. As principais razões do uso excessivo destes dois combustíveis é pelo facto de estes serem mais acessíveis, uso múltiplo (no caso da electricidade), económico e barato (no caso do carvão vegetal) e também pelos hábitos e costumes herdados.

Portanto, a dependência das famílias em relação aos combustíveis na área de estudo é esmagadora. Evidências empíricas sugerem que existem vários factores que influenciam essa situação. Os principais factores são a renda familiar, preços dos combustíveis não-lenhosos disponíveis, pouca disponibilidade de fontes alternativas de energia, características da residência e estrutura da família (idade, sexo, tamanho, escolaridade).

\section{Conflito de interesse}

Os autores declaram não haver conflitos de interesse.

\section{Referências}

Achão, C. C. L. Análise da estrutura de consumo de energia pelo setor residencial brasileiro. Rio de Janeiro: Universidade Federal do Rio de Janeiro, 2003. (Tese de doutorado).

Arthur, F.; Soliano, O.; Mariezcurrena, V. Estudo de avaliação de energias renováveis em Moçambique. Maputo: Banco Central de Moçambique, 2011. (Relatório anual).

Arthur, M.; Bond, C. A.; Wilson, B. Estimation of elasticities for domestic energy demand in

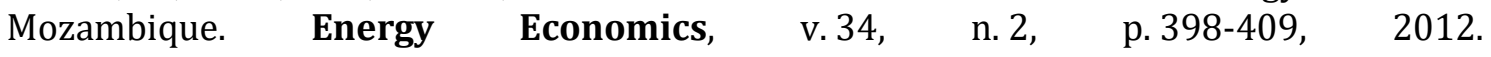
https://doi.org/10.1016/j.eneco.2011.08.006

Ateba, B. B.; Johannes, J.; Fourie, E. The impact of energy fuel choice determinants on sustainable energy consumption of selected South African households. Journal of Energy in Southern Africa, v. 29, n. 3, p. 51-65, 2018. https://doi.org/10.17159/24133051/2018/v29i3a4714

Burgsdorff, S. K. Moçambique energias renováveis em relatório nacional do ponto de situação. 2. ed. Maputo: ALER - Associação Lusófona de Energias Renováveis, 2017.

CENACARTA. Sistema Cartográfico da Cidade da Beira - UCM. Beira: CENACARTA, 2017.

Deus, S. A. J. Análise de consumo da madeira para fins de energia doméstica em três postos administrativos municipais da Cidade de Chimoio. Maputo: Universidade Eduardo Mondlane, 2014. (Projecto final de curso de graduação). 
Eberhard, A. A. Energy consumption patterns and supply problems in underdeveloped areas in South Africa. Development Southern Africa, v. 7, n. 3, p. 335-346, 1990. https://doi.org/10.1080/03768359008439525

Fournier, A. C. P.; Penteado, C. L. C. Energia elétrica no setor residencial à luz do consumo consciente: resultados do estudo de caso no Município de Santo André (SP). Anais do V Encontro Nacional da Anppas, Florianópolis, 2010.

França, V. S. Estudo de caso: análise do consumo energético de uma casa de alto padrão em Porto Velho, Rondônia. Palhoça: Universidade do Sul de Santa Catarina, 2017. (Trabalho de conclusão de curso).

GASMIG - Companhia de Gás de Minas Gerais. Como converter a quantidade de um energético para a equivalente em gás natural. 2019. Disponível em: <http://www.gasmig.com.br/GasNatural/Paginas/Tabela-de-Conversao.aspx>. Acesso em: 23 abr. 2019.

Gil, A. C. Métodos e técnicas de pesquisa social. São Paulo: Atlas, 2008.

Hansen, A. M. D. Padrões de consumo de energia elétrica em diferentes tipologias de edificações residenciais, em Porto Alegre. Porto Alegre: Universidade Federal do Rio Grande do Sul, 2000. (Dissertação de mestrado).

Hinrichs, R. A.; Kleinbach, M.; Reis, L. B. Energia e meio ambiente. 4. ed. Sao Paulo: Cengage, 2013.

INE - Serviço Nacional de Estatística de Moçambique. Manual de consulta de dados. Sistema de Controlo Operativo de Censo de 2017. Maputo: INE, 2017.

IOF - Inquérito ao Orçamento Familiar. Relatório final do inquérito ao orçamento familiar - IOF-2014/15. Maputo: INE, 2015.

Khan, S. S. Percepções de jovens e adultos sobre o risco de contracção do HIV/SIDA nos rituais de purificação: caso dos Bairros Vila Massane e Nhaconjo da Cidade da Beira. Maputo: Universidade Eduardo Mondlane, 2017. (Dissertação de mestrado).

Lusambo, L. P. Household energy consumption patterns in Tanzania. Journal of Ecosystem \& Ecography, S5:007, 2016. https://doi.org/10.4172/2157-7625.S5-007

Luz, N. M. G. F. Análise dos padrões de consumo de famílias portuguesas. Lisboa: Universidade Nova, 2014. (Dissertação de mestrado).

Mahumane, G.; Mulder, P. Mozambique energy outlook, 2015-2030. Data, scenarios and policy implications research. Amsterdam: Faculty of Economy and Business Administration, 2015. (Research Memorandum 2015-7). https://doi.org/10.2139/ssrn.2644144

Manuel, M. T.; Victorino, A. Padrões de consumo de energia no sector residencial: uma revisão bibliográfica. Revista Brasileira de Gestão Ambiental e Sustentabilidade, v. 7, n. 16, p. 605-618, 2020a. https://doi.org/10.21438/rbgas(2020)071610

Manuel, M. T.; Victorino, A. Relações entre padrões de consumo doméstico de energia e níveis de renda familiar: estudo de caso no $14^{\circ}$ Bairro Nhaconjo, Cidade da Beira, Moçambique. Revista Brasileira de Gestão Ambiental e Sustentabilidade, v. 7, n. 16, p. 619-631, 2020b. https://doi.org/10.21438/rbgas(2020)071611

Marconi, M. A.; Lakatos, E. M. Fundamentos de metodologia científica. 4. ed. São Paulo. 1999. 
Ofetotse, E. L.; Essah, E. A.; Yao, R. Trends in domestic electricity consumption in Botswana. TMC Academic Journal, v. 9, n. 2, p. 83-104, 2015.

Secretaria do 14ํㅡㄹ Bairro. Dados estatísticos da população do Bairro de Nhaconjo. Beira: Secretaria do $14^{\circ}$ Bairro, 2019.

Silva, A. S. Administração de infraestruturas de águas e saneamento (AIAS). Mocambique: AIAS, 2017.

Tódero, M. Consumo consciente e percepção do consumidor sobre ações corporativas vinculadas ao conceito de responsabilidade social: um estudo no setor da saúde. Caxias do Sul: Universidade de Caxias do Sul, 2009. (Dissertação de mestrado).

Tso, G. K. F.; Yau, K. K. W. A study of domestic energy usage patterns in Hong Kong. Energy, v. 28, p. 1671-1682, 2003. https://doi.org/10.1016/S0360-5442(03)00153-1

Zhang, T.; Siebers, P.; Aickelin, U. A three-dimensional model of residential energy consumer archetypes for local energy policy design in the UK. Energy Policy, v. 10, n. 47, p. 102-110, 2012. https://doi.org/10.1016/j.enpol.2012.04.027

Informação da Licença: Este é um artigo Open Access distribuído sob os termos da Licença Creative Commons Attribution, que permite uso irrestrito, distribuição e reprodução em qualquer meio, desde que a obra original seja devidamente citada. 